\title{
The Impact of Network Centralization on Relational Capital
}

\author{
Lokhman Hakim Bin Osman* \\ School of Management, Faculty of Economy and Management, Universiti Kebangsaan Malaysia
}

\begin{abstract}
With an increasing degree of connections among firms forming network of economic activities, it is timely to assess the potential of these upon embedded firms. This article presents empirical evidence to that end. It distinguishes between decentralized and centralized network structure that illustrate the difficulties encountered in managing an inter-firm network structure. Although considerable studies has been performed in network issues affecting firms performance, very few research analyse the complicating attributes of a centralized network structure on its effects on firms performance. Thus this article described different attributes of the centralized network and its effects on firms' relational capital outcomes. Using social network analysis methodology this study found that certain structural position occupied by firms in network impacts on its relational capital outcome. This study is significant as it's contributed to prudent management of resources in managing complex network structure. Future research is also discussed.
\end{abstract}

JEL: A290 Z130

Keywords: organizational studies, social network analysis, network

\section{INTRODUCTION}

Managing the complex inter-organizational network can be a difficult task for managers. Structurally, inter-organizational network is virtually formed by the connectivity or links between firms where the integration progressively forms the ultimate structure, which is the inter-organizational network itself (Meyer, Davachi, Ochsner, \& Lieberman, 2018). According to (Y. Kim \& Choi, 2015) a buyer-supplier relationship represents a dyad, or two nodes and one link, in network terms. This form of inter-firm relations or connectivity created the complexity in the inter-organizational network structure. Managing this complexity has taken many approaches. In inter-organizational studies, the concern with cost and efficiency management of inter-relationships has shifted the perspective of inter-organizational network management to the reductionist perspective (Barile \& Saviano, 2018). In reductionist approach, firms or organizations would first develop the detail structure of the inter-organizational network based on known or formal relations. Consequently, firms that are not performing based on strict accounting measures will be removed from the network. Another approach to the interorganizational network management is the dynamic network approach. Network is rich due to the involvement of the parties in different types of inter-organizational relationships (Burt, 2017). What this argument means is that, each and every member of the network holds a position in the network that is rich in 'resources' that only the firm can provide via its embeddedness level in the

*Email : lokhman@ukm.edu.my

Received : 01-02-2019, Accepted : 06-02-2019, Published : 29-04-2019

P-ISSN : 2087-9954, E-ISSN : 2550-0066. DOI : http://dx.doi.org/10.26418/jebik. v8vi1.31154 
network structure. As a result, dynamic structural positions of the firms exist in the network depending of the degree of connectivity of the firms

Thus in this research we argue and suggested that simply removing underperforming firms may not be the best way, as firms may remove partners who are resourceful or more influential, but these characteristics are not visible through good accounting measures. The different pattern of embeddedness in the different type of inter-organizational relationship raise the question of how should we treat the different type of inter-organizational relationships and the pattern of embeddedness. Such questions are important as firms invest heavily in developing and maintaining their network of inter-organizational relationships. Consequently the research questions of this study is the pattern of connectivity of firms embedded in the different type of network relationship?

\section{LITERATURE REVIEW}

\subsection{Embeddedness and Inter-Organizational Relations}

The embeddedness theory argues that inter-firm relations can be in the form of formal commercial transaction activities, such as contractual relations or web of informal social exchanges, including information-sharing and referral activities (Morganson, Major, Streets, Litano, \& Myers, 2015). These two types of inter-firm relations can be either complementary or substitutes of the other. For example, one study that attempted to map the actual map of an upstream inter-organizational network structure was conducted by Burt (2017) and Peltokorpi, Allen, \& Froese (2014). What developed from the research was a complex upstream interorganizational network map of the flow of materials from the upstream suppliers to the focal firm. The map of the upstream inter-organizational network structure shows a complex network structure. A factor that makes this network more complex is the line representing the relation, i.e. material flow, from the suppliers to the focal manufacturer. (Burt, 2017) stressed that these lines represents the material flow among firms in the upstream inter-organizational network structure, thus creating a detailed structure of the complex flow of material in the network. Senge (1994) termed this complexity as detailed complexity. However, in actual fact, according to the embeddedness theory, inter-firm relations are embedded in formal commercial transactions as well as the web informal social exchanges. Other relations such as information-sharing activities are informal yet still occur in the inter-organizational network. Complexity arising from these types of informal relations is dynamic as its structure is subject to the degree of connectivity among the firms in the network (Senge, 1994).

\subsection{Complexity and inter-organizational relationship management}

Complexity is the result of the patterns of interactions among components and the strength of the respective interactions. Complexity in a system IS the interconnected parts in the system that are interdependent of each other in performing their functions (Leleur, 2017). On a similar note, Grösser (2017) defines complexity in a system as being complex in instances where the system consists of a group of related units. Because the inter-organizational network is also a composition of varied yet inter-connected firms it can be argued that the complexity in an interorganizational network arises from the fragmented yet extensive inter-firm relations between the 
varied firms in the network structure (Birkinshaw, 2015). These descriptions of complexity would justify the argument that the network is also complex, and the inter-firm relations represent the inter connectivity between the elements in the system (Sachdev \& Merz, 2017) Using this lens from the literature studies the researcher argue that an understanding of how the inter-organizational structure would emerged in the different types of network relations demands better understanding for the sake of effective management of the inter-organizational network relationships.

\subsection{Inter-organizational involvement and network structure}

The literature indicated two streams of research that studies how the inter-organizational network ties influence the management of the inter-organizational network. The first stream of research is in the domain of marketing and inter-organizational network management. This literature stream has studied the embeddedness in the buyer supplier relationship focusing on the organization as the unit of analysis, relationship quality, duration and type and has indicated that these attributes are success factors in the buyer supplier alliances (Martins, Rossoni, Duarte, \& Martins, 2017). Even though this stream of research generally centers on the relationship attributes in dyadic ties, this stream of research was successful in determining several essential relational concepts that are generalizable to the overall inter-organizational network. Unfortunately, the resulting structure of the involvement in the network of multiple buyersupplier organizations have rarely been researched in the literature (Kim, 2014). The second stream of literature addresses the question of the best fit. This line of study attempts to determine the best structure or configuration of the inter-organizational network to meet the challenge of market. This stream of literature is primarily concerned with issues such as inclusion or exclusion of buyers or suppliers, mapping the structure of the inter-organizational network, and how clusters of the buyer-supplier relationships should be managed (Villena \& Cheng, 2016). Nevertheless, to our knowledge, there is no known best configuration of buyer supplier organizations operating within the network. This issue is further complicated by the fact that the relative success of network structural configuration is predominantly related to the relational context of the buyer supplier organizations interrelatedness (Kang, Min, \& Lee, 2016). These streams of literature provide a fundamental justification in their explanation of dynamics of interorganizational network structure. In addition, the themes ignore the interactive elements of the connectivity, whereby organizations obtain information from this connectivity. It is important to note that, although the buyer supplier relationship is essentially a dyadic tie between a buyer and a supplier, the outcomes and processes associated with the ties can be linked to the social network structure within which the buyer-supplier organizations are embedded in.

\subsection{Detailed and Dynamic Complexity of Network Relations}

In this study, the researcher also argues that formal contract ties and informal ties of the interorganizational network relations constitute networks among firms in the inter-organizational network structure. Zhou, Zhang, Sheng, Xie, \& Bao (2014) found that governance of inter-firm relationships involves formal and informal coordination. Under formal coordination or inter-firm relations, Lina \& King (2018) argue that long-term resource dependencies between firms or organizations are forged to ensure future commitments and cooperation. Examples of this formal coordination include inter-firm relations such as contract ties and flow of materials resulting from the contract (Liu, Huang, Dou, \& Zhao, 2017). An important characteristic of the formal inter- 
firm relation is the detailed existence of a hierarchical or a top-down approach to the governance of the inter-firm network. Through the hierarchical or top-down approach governance benefits such as administration, and control are realized (Brailly, Favre, Chatellet, \& Lazega, 2016). On the other hand, Osman (2015) argue that informal coordination relates to inter-firm relations of communication that emerge from informal social relationships. Thus, inter-firm relationships under the informal coordination are largely dynamic and voluntary in nature. Based on this argument, clearly a firm's level of embeddedness in a network would involve a continuum of inter-firm relations from formal to informal coordination. This may include network ties such formal contract ties and information-sharing ties.

\section{METHODOLOGY}

For the purposes of this study, an inter-organizational network of a small maritime industry seemed to be an ideal setting. An inter-organizational network in the maritime industry is a material-intensive enterprise. The focal research site of this study is located in the Peninsular Malaysian cluster. The network, labeled here as APMMHQ-1, is part of the inter-organizational network. APMMHQ-1 is a company in the Malaysian shipbuilding industry involved in ship repairs, maritime, engineering and related service provider matters. To date, the company has awarded contracts to local vendors and suppliers totaling RM 31 million for the development of small vessels in the region. APMMHQ-1's inter-organizational network was considered to be one of the best supply systems in the region through its Integrated Logistic Support (ILS) programs. Top level management was approached for possible participation in the study. After several communications about the goal of this study and the potentials' benefits for the APMMHQ-1inter-organizational network, positive commitments were received from the top management to participate in and grant participation for this study.

In social network analysis, the network structure needs to be searched for and not assumed from previous related literature Osman (2017). Consequently, different network analysis routines were applied to explore patterns of connectivity between the firm's organizations that are embedded in the APMMHQ-1inter-organizational network and to examine the structural characteristics of these entities. These analyses were performed using the software package. The first step in exploratory network analysis is to determine whether the data displays any interesting patterning at all (Osman, 2017). This can be done by combining the visualization techniques with mathematical algorithms to search for an optimum arrangement of actors and links. The objective is to find the optimal layout to position the nodes on a graph in a way that accurately represents the structural patterning of the network by depicting the pairs that are socially closest in the graphic image. For this purpose, this study adopted a spring-embedding visualization method in the UCINET program whereby a network layout is computed using a force-directed algorithm. 


\section{RESULTS}

\subsection{Detailed inter-organizational network structure}

The detailed inter-organizational (based on contract of material flow) structure of the APMMHQ-1 inter-organizational network for the product RHIB was first developed. Following the inter-organizational network structure for the RHIB was developed based on the archival review and discussion that the researcher conducted with key informants from AMPPHQ-1. These consisted of, namely: two tiers one firms and one tier two firms concerning the flow of materials from the upstream firms to the focal firm, i.e. APMMHQ-1 for the product RHIB. Based on the data collected, the following figure depicts the inter-organizational network structure of APMMHQ-1 for the supply of materials for the product RHIB. In figure 1, the firms are colored based on their positions in the inter-organizational network structure. APMMHQ-1 is the focal firm in this centralized inter-organizational network structure and its colour in red. Firms in tier one have a blue colour and consist of seven firms. Tier two firms are represented in green and consist of 16 firms. Finally, firms in tier three are purple in colour and consist of twelve firms.

The structure in figure 1 indicates a hierarchical structure of the APMMHQ-1 interorganizational network for the supply of materials and services for the product RHIB. Flow of materials for the production of the RHIB consists mainly of three tiers of suppliers having a total of 37 firms. The largest number of suppliers or firms in the inter-organizational network structure resides in tier two of the upstream inter-organizational network consisting of 17 firms. The logic behind this is that the firms in tier two are the firms that manufacture the raw materials from tier three firms into work in process (WIP) components or parts for the tier one supplier and, ultimately, the focal firm or manufacturer. This hierarchical structure is normally the result of the flow of resources in the APMMHQ-1 upstream inter-organizational network network. In the following section, the researcher presents the network map of four network ties, i.e.: contract tie, information-sharing tie, referral made tie and referral received tie.

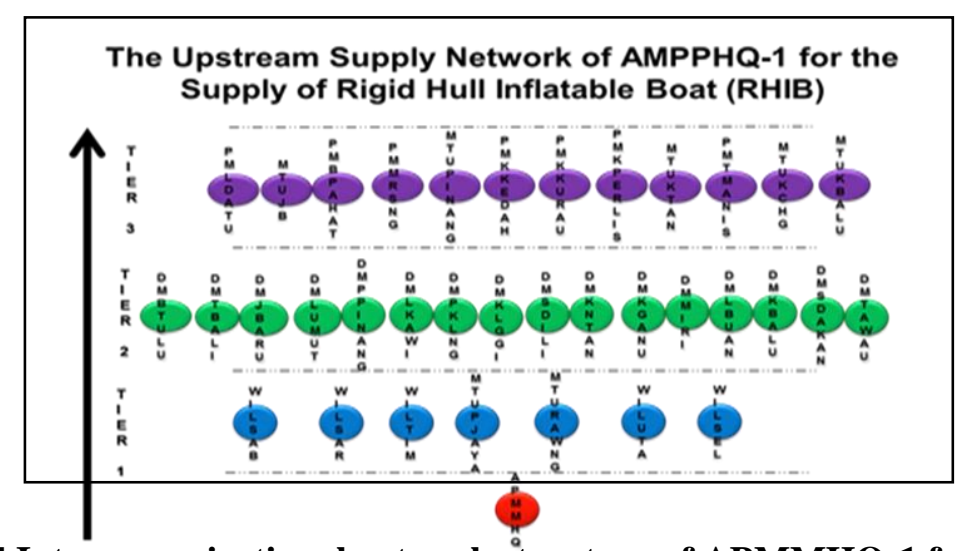

Figure 1 Detail Inter-organizational network structure of APMMHQ-1 for the product RHIB

\subsection{Dynamic inter-organizational network structure}

In this section, the researcher discusses the dynamic inter-organizational network structure. Figure 2 displays the data sets that indicate the cores for an information-sharing tie network. 
Figure 2 demonstrates the sociogram with embeddedness characteristic in data sharing ties. From a general viewpoint, Figure 2 demonstrates that the densely connnected firms in the data sharing tie are likewise to a great extent among the focal firms in the supply framework. For instance, APMMHQ-1, WILSAB-31, MTUPJAYA-2, WILSEL-12, and WILUTA-4 are among the firms that are viewed as extremely focal or central by different firms (red shading). The size of the squares likewise shows that they are among the most very embedded in view of degree centrality in the data sharing tie. Notwithstanding that, firms that appraised in low tier likewise display low embeddedness scores in light of degree centrality in the data sharing tie. These organizations include: DMTAWAU-34, DMKBALU-33, MTUKBALU-37, MTUKCHNG-30, PMMRSNG17, PMKKURAU-19, DMKKNTAN-21, DMKGANU-22, DMMIRI28, MTUKTAN-24, and DMSDAKAN-22 individually. Fundamentally, this investigation discovered one fascinating finding of how exceedingly embedded firms in the data sharing tie may not be among the most noteworthy in the supply tiers, i.e., the MTURAWNG-3. This might be on account of the information sharing sharing is thought to be a casual type of ties that are manufactured with no arrangements or terms, for example, in contract ties. In legally binding ties (i.e. contract ties), when there is an arrangement of terms or guidelines overseeing the connections, the firm may tend to manufacture ties with others that have more assets, (for example, materials). Then again, in the informations sharing ties, the association between the organizations is framed with no guidelines or controls administering its casual nature.

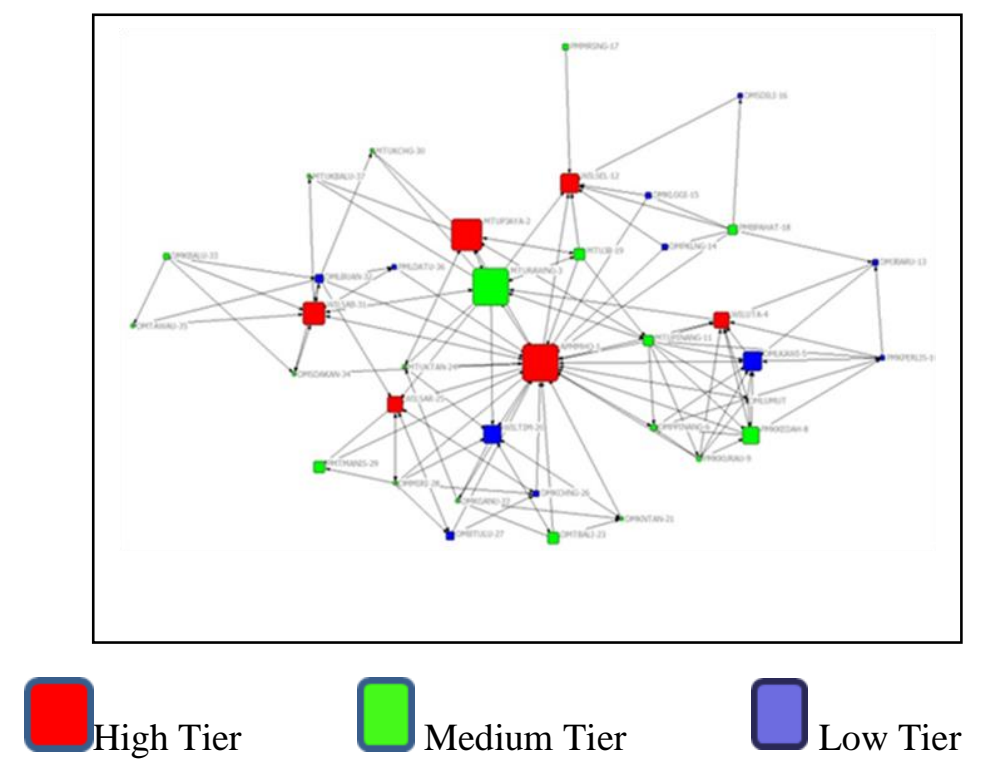

Figure 2 Supply network with color on the nodes representing tier level

\section{DISCUSSION AND CONCLUSION}

The goal of the exploratory network analysis was to determine the pattern of detailed and dynamic structure of firms in the inter-organizational network structure in relation to the type of network ties being considered. The distribution of the network structural measures of 
embeddedness show an interesting pattern. Using the exploratory network analysis, the researcher established that the embeddedness of firms in the inter-organizational network is related to the formal versus informal classification of network ties. Overall, relationship networks with high formality are less connected and less dense in the network. The detailed network plots and network structural measures indicate that, in the formally-integrated relationship, firms are less involved or embedded in the network structure. The network structural measures also indicated that firms that are embedded in informal ties (such as information-sharing ties) are more actively connected to each other than formal contractual ties. This could mean that informal relationships carry more weight than formal relationships. Our finding is consistent with work examining the relationships between a supplier's embeddedness in the supply network and the supplier's performance posited that firms are more embedded within their extended network through their informal social networks. Because of that, managers must pay higher attention to the pattern of embeddedness of these firms. By doing so, managers may do a better job of selecting partners for long-term relationships and may also find value in maintaining relationships with poorly performing firms who may potentially act as a conduit

Overall, in answering research question of this study, the visual analysis shows that the firm network embeddedness in the inter-organizational network is contingent upon the type of firms' relationship. The findings from the exploratory network analysis presented in the earlier sections described the interesting pattern and effects of firms' embeddedness. The findings also illustrated the contingent relationship between the firms' embeddedness and the network degree of formality in the network structure. This has a resultant impact upon knowledge and management of the network.

This study contributes to the literature by testing the implications of firms' embeddedness in formal and informal networks of inter-firm relations simultaneously. It also tests the interaction implications of the positions in the two classifications of inter-firm relations. To the best of the researcher's knowledge, research has not yet looked at the embeddedness effects of the firms in the two networks in the context of the inter-organizational network. Thus, this research makes the initial step into understanding of the impact of multiple inter-firm networks on the firms in the centralized network structure. For future research, the researcher proposes that the framework of this study be investigated in other fields. The ship building industry context of the upstream supply chain, upon which this study has conducted an investigation, may characteristically differ from another industry and fields. As such, the researcher proposes that the design of this research be tested in the context of other industries or fields.

\section{REFERENCES}

Barile, S., \& Saviano, M. (2018). Complexity and Sustainability in Management: Insights from a Systems Perspective. Social Dynamics in a Systems Perspective. Springer, Cham. https://doi.org/DOI https://doi.org/10.1007/978-3-319-61967-5_3

Birkinshaw, J. (2015). Are You Managing Complexity? London Business School Review.

Brailly, J., Favre, G., Chatellet, J., \& Lazega, E. (2016). Embeddedness as a Multilevel Problem: A Case Study in Economic Sociology. Social Networks, 44, 319-333. https://doi.org/https://doi.org/10.1016/j.socnet.2015.03.005 
Burt, R. S. (2017). Structural Holes versus Network Closure as Social Capital. In Social Capital (p. 26). New York: Routledge.

Grösser, S. N. (2017). Complexity Management and System Dynamics Thinking. In Dynamics of Long-Life Assets. https://doi.org/10.1007/978-3-319-45438-2

Kang, H., Min, J., \& Lee, J. K. (2016). The Effects of Uncertainties on Network Embeddedness and the Mediating Effect of Information Sharing. Journal of Marketing Thought, 2(4), 115.

Kim, D.-Y. (2014). Understanding Supplier Structural Embeddedness: A Social Network Perspective. Journal of Operations Management, 32(5), 219-231. https://doi.org/https://doi.org/10.1016/j.jom.2014.03.005

Kim, Y., \& Choi, T. Y. (2015). Deep, Sticky, Transient, and Gracious: An Expanded BuyerSupplier Relationship Typology. Journal of Supply Chain Management, 51(3), 61-86. https://doi.org/https://doi.org/10.1111/jscm.12081

Leleur, S. (2017). The Meaning of System: Towards a Complexity Orientation in Systems Thinking. In Decision Management: Concepts, Methodologies, Tools, and Applications (pp. 67-82). IGI Global. https://doi.org/10.4018/978-1-5225-1837-2.ch005

Lina, X., \& King, C. (2018). Too Much of a Good Thing? Examining How Proactive Personality Affects Employee Brand Performance Under Formal and Informal Organizational Support. International Journal of Hospitality Management, 68, 12-22. https://doi.org/10.1016/j.ijhm.2017.09.007

Liu, X., Huang, Q., Dou, J., \& Zhao, X. (2017). The Impact of Informal Social Interaction on Innovation Capability in the Context of Buyer-Supplier Dyads. Journal of Business Research, 78, 314-322. https://doi.org/https://doi.org/10.1016/j.jbusres.2016.12.027

Martins, G. S., Rossoni, L., Duarte, A. L. C. M., \& Martins, R. S. (2017). Supply Chain Relationships: Exploring the Effects of both Relational and Structural Embeddedness on Operational Performance. International Journal of Procurement Management, 10(5), 639664. https://doi.org/10.1504/ijpm.2017.10006799

Meyer, M. L., Davachi, L., Ochsner, K. N., \& Lieberman, M. D. (2018). Evidence That Default Network Connectivity During Rest Consolidates Social Information. Cerebral Cortex, 29(5), 1910-1920. https://doi.org/https://doi.org/10.1093/cercor/bhy071

Morganson, V. J., Major, D. A., Streets, V. N., Litano, M. L., \& Myers, D. P. (2015). Using Embeddedness Theory to Understand and Promote Persistence in STEM Majors. The Career Development Quarterly, 63(4), 348-362. https://doi.org/https://doi.org/10.1002/cdq.12033

Osman, L. H. (2015). A Social Network Model of Supply Chain Management in Formal and Informal Inter-Firm Engagement. Logforum, 11(4), 359-373. https://doi.org/10.17270/J.LOG.2015.4.5

Osman, L. H. (2017). True Nature of Supply Network Communication Structure. International Research Journal of Business Studies, 9(1), 1-14. https://doi.org/10.21632/irjbs.9.1.1-14

Peltokorpi, V., Allen, D. G., \& Froese, F. (2014). Organizational Embeddedness, Turnover 
Intentions, and Voluntary Turnover: The Moderating Effects of Employee Demographic Characteristics and Value Orientations. Journal of Organizational Behavior, 36(2), 292312. https://doi.org/https://doi.org/10.1002/job.1981

Sachdev, H., \& Merz, R. (2017). Managing Material and Logistics Embeddedness: Material Buyers' Perspective. I-Manager's Journal on Management, 11(4), 1-20. https://doi.org/https://doi.org/10.26634/jmgt.11.4.13448

Senge, P. M. (1994). The Fifth Discipline Fieldbook: Strategies and Tools for Building a Learning Organization. Crown Business.

Villena, V. H., \& Cheng, L. (2016). The Benefits and Downsides of Common Supply Chain Partners. In Academy of Management Proceedings. https://doi.org/https://doi.org/10.5465/ambpp.2016.10673abstract

Zhou, K. Z., Zhang, Q., Sheng, S., Xie, E., \& Bao, Y. (2014). Are Relational Ties Always Good for Knowledge Acquisition? Buyer-Supplier Exchanges in China. Journal of Operations Management, 32(3), 88-98. https://doi.org/https://doi.org/10.1016/j.jom.2014.01.001 